\title{
Bir İnsansız Hava Aracının İtki ve Manevra Hareketlerinde Gövde İçi Basınçlı Hava Kullanımı
}

\author{
Tamer Saraçyakupoğlu ${ }^{1 *}$, Heyzem Doğukan Delibaş², Ahmet Devlet Özçelik ${ }^{3}$ \\ ${ }^{1 *}$ Istanbul Gelisim University, Department of Aeronautical Engineering, 34315, Istanbul, Turkey, (ORCID: 0000-0001-5338-726X), \\ dr.tamer@tamersaracyakupoglu.com.tr
}

2Istanbul Gelisim University, Department of Aircraft Maintenance and Repair, 34315, Istanbul, Turkey, (ORCID: 0000-0002-4423-7769), hddelibas@gelisim.edu.tr
${ }^{3}$ Istanbul Gelisim University, Department of Aircraft Maintenance and Repair, 34315, Istanbul, Turkey, (ORCID: 0000-0003-4696-2232), adozcelik@gelisim.edu.tr

(2nd International Conference on Access to Recent Advances in Engineering and Digitalization (ARACONF)-10-12 March 2021)

(DOI: $10.31590 /$ ejosat.898449)

ATIF/REFERENCE: Saraçyakupoğlu, T., Delibaş, H.D., Özçelik, A.D. (2021). Bir İnsansız Hava Aracının İtki ve Manevra Hareketlerinde Gövde İçi Basınçlı Hava Kullanımı. Avrupa Bilim ve Teknoloji Dergisi, (24), 81-86.

Öz

Bu çalışmada bir İnsansız Hava Aracı (UAV) üzerinde itki sistemi olarak basınçlandırılmış havanın kullanımı sayısal determinasyon yöntemi ile ortaya konmaktadır. Söz konusu İHA, Eklemeli Üretim (EÜ) yöntemi ile üretilecektir. Tasarlanan İHA üzerinde yunuslama, yatış ve sapma hareketleri her bir kumanda yüzeyi üzerinde yerleştirilen lüle (nozzle) vasıtasıyla sağlanacaktır. Ultem 1010 malzeme kullanılarak gerçekleştirilecek olan proje kapsamında İHA’nın istenen kumandaları vermesi için üzerine elektronik donanım (Aviyonik) yerleştirilecektir. Bir fırlatıcı sistem ile ilk hareketinin sağlandığı İHA irtifa, istikamet ve sürat bilgilerini gerçek zamanlı olarak yer istasyonuna akyataracaktır. Uçuşu etkileyen en kritik unsurlardan olan rüzgâr bilgisi vektörel olarak İHA tarafından algılanacaktır. İHA, rüzgâr şiddet ve istikamet bilgilerine göre doğrulama yaparak yol noktalarına (waypoint) ilerleyecektir. Yol noktaları İHA yerdeyken bir veri seti olarak girilebileceği gibi, uçuş esnasında da yeniden programlama yapılabilecektir. Herhangi bir arıza ya da bağlantı kopması durumunda İHA kalkış yaptığı istasyona geri dönecektir. Çalışmanın sonunda, mevcut imkânlarla söz konusu İHA’nın üretilebelirliği ortaya konarak sessizlik, enerji tasarrufu gibi konularda fayda sağladığı belirlenmiştir.

Anahtar Kelimeler: İHA, Basınçlı hava, Eklemeli üretim, Üç eksenli hareket

\section{The Use Of Pressurized Air Inside the Fuselage Of An Unmanned Aerial Vehicle for Thrust and Maneuver Movements}

\begin{abstract}
In this study, the use of pressurized air as a propulsion system on an Unmanned Aerial Vehicle (UAV) is demonstrated by the numerical determination method. The mentioned UAV will be produced by Additive Manufacturing technology. The pitch, roll, and yaw movements on the designed UAV will be provided through a nozzle placed on each control surface. Within the scope of the project to be carried out using Ultem 1010 material, the avionics will be implemented on the UAV to perform the entered data. A launcher system will propel the UAV for initial movement and the flight altitude, heading and speed information of the UAV will be transferred to the ground station in real-time. Wind information, which is one of the most critical factors affecting flight, will be detected by the UAV vectorially. The UAV will proceed to the waypoints by verifying the wind amplitude and direction information. Waypoints can be entered as a data set while the UAV is on the ground, as well as reprogramming during flight. In case of any malfunction or disconnection, the UAV will return to the station where it took off. At the end of the study, with current capabilities, it was determined that the manufacturability for mentioned UAV was possible providing benefits such as silence and energy saving.
\end{abstract}

Keywords: UAV, Pressurized air, Additive manufacturing, three axis movement

\footnotetext{
*Sorumlu Yazar: dr.tamer@tamersaracyakupoglu.com.tr
} 


\section{Giriş}

İHA lar günümüzde oldukça yaygın bir kullanım alanına sahiptir. Genel tanımlama itibariyle otopilot yardımı le ya da uzaktan kumanda sistemi kullanılarak kumanda verilen ve içinde uçağ 1 çalıştıran ya da operasyon personelin bulunmadığ 1 hava araçlarıdır demek mümkündür. Askeri kullanımının yanı sıra, arama-kurtarma, tarım, film yapımı, lojistik, hobi, arkeoloji ve madencilik gibi alanlarda kullanımları söz konusudur (Ateş ve Gündüz, 2020). Son dönemde İHA'ları yapısal ve aerodinamik tasarım optimizasyonlarında "çevre dostu" olma özelliğinin özellikle arandığ kazandığ1 gözlemlenmektedir (Hermanutz, ve Hornung, 2020).

Takat sistemi olarak, elektrik motorlu, fosil yakıt kaynağı ya da her ikisinin birden kullanıldığı hibrit yöntemler kullanılmaktadır. Ayrıca, yerden kablo ile bağlı olan ve kablo ile bağlı olmayan İHA türleri de mevcuttur (Küçükçelebi ve Yaldız, 2020). Aşağıdaki havada kalış (flight time) süreleri açısından sıralama yer almaktadir:

- Mikro/Mini 1-2 saat,

- Taktiksel, 2-48 saat,

- $\quad$ Stratejik 24-48 saat

- Özel Görevli 3->48 saat (Yiğit, Yazar ve Karakoç, 2018)

Görüldüğü üzere 48 saat ve üzerinde yer alan zamanlarda İHA'ların görev yapabildiği gözlemlenmektedir. $\mathrm{Bu}$ husus, İHA'ların insanlı hava araçlarına yönelik en önemli üstünlüklerinden birisi olarak kabul edilmektedir (Ulloa, Nunez, Lin ve Rey, 2018). Bu kadar uzun süre havada kalmak yakıt kaynağını optimize edilerek kullanılması zorunluluğunu da beraberinde getirmektedir.

Yapılan literatür taramasında, elektrikli sistemle tahrik edilen bir sabit kanat İHA'da toplam kalkış ağırlığının yarısından fazlasının itki sistemi ve itki sistemine güç sağlayan PEMFC (Proton Exchange Membrane Fuel Cell) sistemine harcandı̆̆ 1 görülmektedir (Özbek, Yalin, Ekici ve Karakoç, 2020). Bir başka çalışmada ise İHA'nın enerji yönetim sistemi ele alınmış ve hibrit yöntem uygulanmasını mevcut teknoloji seviye açısından zorlukları ortaya konmuştur (Wang, Zhao, Li, Wang, Huang, You, ve Becker, 2020). EÜ ile İHA üretimi konusunda kullanılan malzemelere yönelik yapılan çalışmalarda ABS ve Ultem gibi malzemelerin kıyaslanması yapılmıştır. Bu çalışmada ise, itki sistemi olarak gövde içerisinde basınçlandırılmış hava kullanımı söz konusudur. Ultem 1010 malzeme kullanarak EÜ yöntemi ile \%20 infill baskı kullanılarak üretim metoduna göre çalışma yapılmıştır. Literatür çalışmaları Ultemin, ABS, PLA gibi mukayese edilen diğer malzemelere kıyasla en yüksek mekanik değerlere sahip olduğunu ortaya konmuştur (Goh, Agarwala, Goh, Dikshit, Sing ve Yeong, 2017).

\section{Materyal ve Metot}

\subsection{Görev Profili, Faydalı Yüke Bağlı Kütle- Denge Hesabı}

Görev profili ve faydalı yük hava aracının ağırlığının hesaplanmasında temel alınan değerlerdir. Görev profili ise Şekil 1 'de yer alan uçuş safahatlarının süreçleri ile ortaya çıkmaktadır.

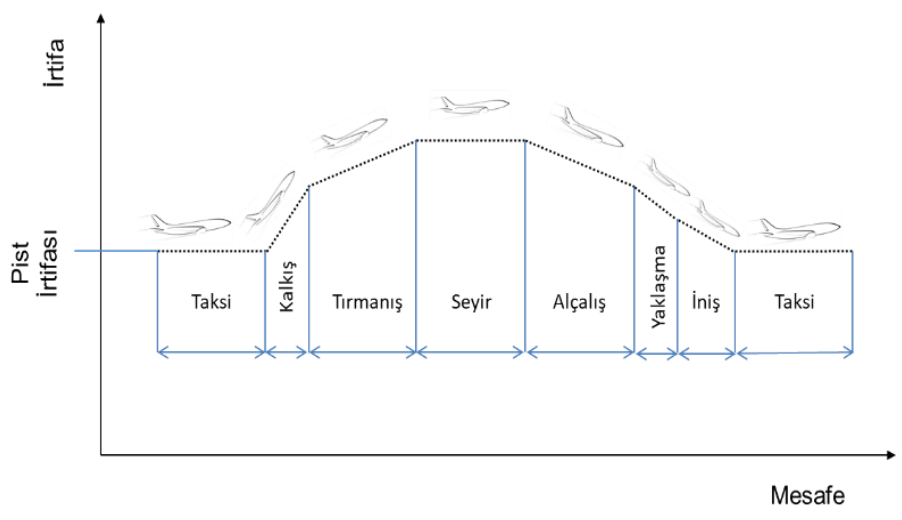

Şekil 1. Uçuş Safhaları (Saraçyakupoğlu, 2020)

Bu projeye konu olan İHA'nın üretimi için deniz seviyesinden kalkış, 3000 feet irtifaya tırmanış, 3000 feet'te 100 km seyrüsefer uçuş, deniz seviyesine alçalış ve ardından da iniş süreçleri temel alınmıştır. Burada $\mathrm{W}_{0}$, azami kalkış ağırlığı (Maximum Taker-Off Weight) için eşitlik;

$W_{0}=\frac{\mathrm{W}_{\text {Payload }}}{\left(1-\frac{\mathrm{W}_{\mathrm{f}}}{\mathrm{W}_{0}}-\frac{\mathrm{W}_{\mathrm{e}}}{\mathrm{w}_{0}}\right)}$

olarak verilmektedir söz konusu eşitlikte;

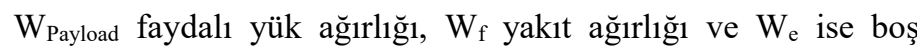
ağırlıktır. İteratif olarak AKA'nın belirlenmesine yönelik çalışma Tablo 1'de sunulmaktadir.

Tablo 1. AKA'nın Iteratif Olarak Belirlenmesi

\begin{tabular}{lccccr}
\hline $\begin{array}{l}\mathbf{W}_{\mathbf{0}} \\
\mathbf{( k g})\end{array}$ & $\begin{array}{c}\mathbf{W}_{\text {payload }} \\
\mathbf{( k g )}\end{array}$ & $\mathbf{W}_{\mathrm{e}} / \mathbf{W}_{\mathbf{0}}$ & $\mathbf{W}_{\mathbf{0}}$ & Fark & $\begin{array}{r}\mathbf{W}_{\mathbf{0}} \\
\mathbf{( k g )}\end{array}$ \\
\hline 7,25 & 1,8 & 0,781 & 20,182 & 3,682 & 7,4745 \\
8,16 & 1,8 & 0,778 & 19,874 & 1,874 & 8,154 \\
8,61 & 1,8 & 0,775 & 19,599 & 0,099 & 8,8335 \\
9,5 & 1,8 & 0,772 & 19,353 & 1,647 & 9,513 \\
9,97 & 1,8 & 0,769 & 19,129 & 3,371 & 10,1925 \\
\hline
\end{tabular}

Söz konusu tabloda basınçlandırılmış hava kullanılması sebebiyle $\mathrm{W}_{\mathrm{f}}$ değeri, 0 olarak kabul edilmiştir. Şekil 2'de görüldüğü üzere sıkıştırılmış hava gövde içerisinde özel olarak tasarlanmış haznede yer almaktadir.

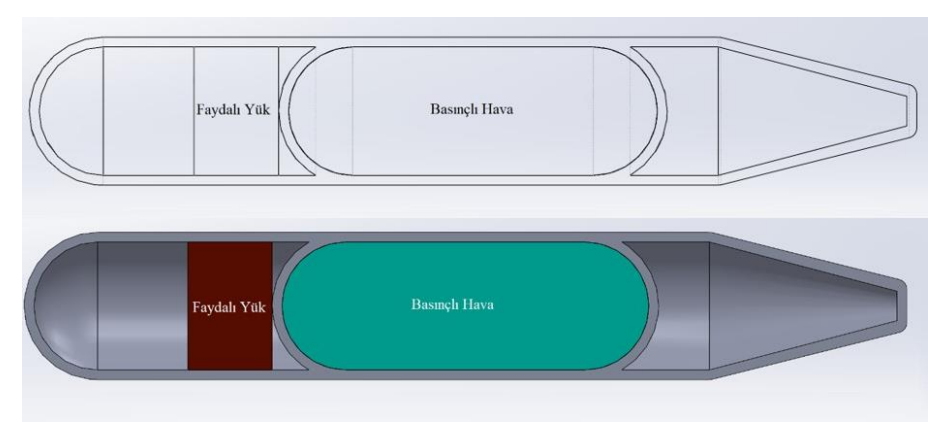

Şekil 2. Basınçlandırılmış Hava Haznesinin Gövde İçerisinde Gösterimi 
Faydalı yük belirleme ve optimizasyon kapsamında ise yine bir iteratif çalışma gerçekleştirilmiştir. Sirasıyla $1 \mathrm{~kg}, 1,5 \mathrm{~kg}$ ve $2 \mathrm{~kg}$ için AKA belirleme çalışmaları iteratif olarak geçekleştirilmiştir.

Tablo 2.Faydalı Yükün Iteratif Olarak Belirlenmesi

\begin{tabular}{|c|c|c|c|c|c|}
\hline $\mathrm{W}_{\mathbf{0}}(\mathrm{kg})$ & $W_{\text {payload }}(\mathbf{k g})$ & $\mathbf{W}_{\mathrm{e}} / \mathbf{W}_{\mathbf{0}}$ & $\mathbf{W}_{\mathbf{0}}$ & Fark & $\mathbf{W}_{0}(\mathrm{~kg})$ \\
\hline \multicolumn{6}{|c|}{ Faydalı Yük = 1 kg } \\
\hline 4,0823 & 2,205 & 0,806 & 11,339 & 2,339 & 4,077 \\
\hline 4,5359 & 2,205 & 0,801 & 11,097 & 1,097 & 4,53 \\
\hline 4,9895 & 2,205 & 0,797 & 10,889 & $-0,111$ & 4,983 \\
\hline 5,4431 & 2,205 & 0,794 & 10,706 & $-1,294$ & 5,436 \\
\hline 5,8967 & 2,205 & 0,791 & 10,543 & $-2,457$ & 5,889 \\
\hline \multicolumn{6}{|c|}{ Faydalı Yük = 1,5 kg } \\
\hline 5,8967 & 3,3075 & 0,791 & 15,815 & 2,815 & 5,889 \\
\hline 6,3503 & 3,3075 & 0,788 & 15,597 & 1,597 & 6,342 \\
\hline 6,8039 & 3,3075 & 0,785 & 15,4 & 0,4 & 6,795 \\
\hline 7,2575 & 3,3075 & 0,783 & 15,221 & $-0,779$ & 7,248 \\
\hline 7,7111 & 3,3075 & 0,78 & 15,056 & $-1,944$ & 7,701 \\
\hline \multicolumn{6}{|c|}{ Faydalı Yük = 2 kg } \\
\hline 7,484274 & 4,41 & 0,781 & 20,182 & 3,682 & 7,4745 \\
\hline 8,164663 & 4,41 & 0,778 & 19,874 & 1,874 & 8,154 \\
\hline 8,845051 & 4,41 & 0,775 & 19,599 & 0,099 & 8,8335 \\
\hline 9,52544 & 4,41 & 0,772 & 19,353 & $-1,647$ & 9,513 \\
\hline 10,20583 & 4,41 & 0,769 & 19,129 & $-3,371$ & 10,1925 \\
\hline
\end{tabular}

Tasarım lift katsayısı hesaplanması için standart atmosferik koşullar (ISA $+15^{\circ} \mathrm{C}$ ) şartlar göz önünde bulundurulmuştur. Burada $C_{L}$, Reynolds değeri baz alınarak ve kalınlıklık oranı ile 4 farklı kanat profile belirlenmiştir. Bu kanat profilleri $D$ and $C_{M}$ değerlerine göre birbirleri ile mukaye edilmişlerdir. Azami sürat, ask1 sürati-perdövites sürati (Stall Speed) ve en iyi menzil kıyaslamalarına göre en ideal kanat profili belirlenmiştir. Burada $C_{L}$ kaldırma (lift) katsayısı, $C_{\mathrm{D}}$, sürükleme (drag) katsayısı ve $C_{\mathrm{M}}$ ise moment katsayısını ifade etmektedir.

3000 feet irtifada;

$\rho_{\infty}=1.112 \mathrm{~kg} / \mathrm{m}^{3}$

$\mathrm{g}=9.79 \frac{\mathrm{m}}{\mathrm{s}^{2}}$

$\mu_{\infty}=1.758 \times 10^{-5} \mathrm{~N} . \mathrm{s} / \mathrm{m}^{2}$

(4)

Olarak ifade edilmektedir. Burada $\rho_{\infty}$,yoğunluk, g yerçekimi ivmesi ve $\mu_{\infty}$ ise akışmazlık (viskozite) değerleridir.

Kabul edilen değerler ise aşağıda sunulmaktadır.

e-ISSN: 2148-2683
$\mathrm{V}_{\max }=33.3 \mathrm{~m} / \mathrm{s}=120 \mathrm{~km} / \mathrm{h}$

(5)

$\mathrm{W}=8.834 \mathrm{~kg}$

$\mathrm{b}=3 \mathrm{~m}$

Burada $V_{\text {max }}$ is azami sürat, $\mathrm{W}$ ağırlık ve $\mathrm{b}$ ise ortalama kanat açıklığıdır.

$\mathrm{Bu}$ değerler doğrultusunda kanat kord (veter) hattı uzunluğu ise;

$\mathrm{c}=\frac{\mathrm{b}}{\mathrm{AR}}$

elde edilmektedir. Planform (Aspect Ratio) değeri ise;

$\mathrm{AR}=\frac{\mathrm{b}^{2}}{\mathrm{~s}}$

olarak elde edilmektedir. Burada S kanat alanıdır

Sonuç olarak

$S=0.6 \mathrm{~m}^{2}$

ve

$\mathrm{c}=0.2 \mathrm{~m}$

olarak elde edilir.

Kaldırma kuvvetinin ağırlığa eşit olduğundan yola çıkarak

$\mathrm{C}_{\mathrm{L}}=\frac{\mathrm{L}}{\left(\frac{1}{2} \times \rho_{\infty} \times \mathrm{V}_{\infty}^{2} \times \mathrm{S}\right)} \quad \mathrm{L}=\mathrm{W}$ (12)

Elde edilir. Kaldırma katsayısı $C_{L}$,

$\mathrm{C}_{\mathrm{L}}=0.22$

Olarak hesaplanır.

\subsection{Reynolds Değeri Hesaplaması}

Reynolds değerinin hesaplanması için, perdövites sürati, ortalama veter ve deniz seviyesi şartları göz önünde bulundurulmuştur. ISA $+15^{\circ} \mathrm{C}$ şartlarında;

$\begin{aligned} \rho_{\infty} & =1.225 \mathrm{~kg} / \mathrm{m}^{3} \\ \mu_{\infty} & =1.789 \times 10^{-5} \text { N.s } / \mathrm{m}^{2}\end{aligned}$

Olarak belirlenmiştir. Bu durumda Re değeri;

$\operatorname{Re}=\frac{\left(\rho_{\infty} \times V_{\infty} \times c\right)}{\mu_{\infty}}$

Formülünden hesaplanabilir. Burada $\mathrm{V}_{\infty}$ serbest akış süratidir.

$\operatorname{Re}=2.36 \times 10^{5}$ 
3000 feet irtifada, azami sürat ve ortlama veter şarları göz önüne alındığında;

$\operatorname{Re}=4.21 \times 10^{5}$

Elde edilmektedir

Kanat profili seçimi için kalınlık (cidar) oranı hesaplaması oldukça önemlidir. Bu hesaplama için Mach sayısı üzerinden işlem yapılması gerekmektedir. Seyrüsefer şartlarında azami sürat için Mach sayısı;

$\mathrm{M}=\frac{\mathrm{V}_{\infty}}{\mathrm{a}}$

Olarak verilmektedir. Burada M, Mach sayısı ve a ise ses hızıdır.

$\mathrm{V}_{\max }=33.3 \mathrm{~m} / \mathrm{s}=120 \mathrm{~km} / \mathrm{h}$

Azami sürat değeri olarak verilmiştir. Bu durumda

$\mathrm{a}=336.4 \mathrm{~m} / \mathrm{s}(@ 3000$ feet $)$

$\mathrm{M}=0.1$

olarak hesaplanmaktadır.

Mach sayısının belirlenmesine yönelik cidar oranının kullanımı (Raymer, 1989) tarafindan parametrik olarak verilmektedir. Söz konusu tabloların kullanımı ile cidar kalınlığı;

$\mathrm{t} / \mathrm{c}=0.12$

olarak bulunmaktadır.

\section{Araştırma Sonuçları ve Tartışma}

\subsection{Kanat Profili Oluşturma}

Kanat tasarımı hava aracı tasarımın en kritik safhası olarak değerlendirilmektedir. Bu kapsamda, elde edilen veriler 1şı̆̆ında, kanat profili belirlemeye yönelik kıyaslama çalışması Tablo 3 'te sunulmaktadır. NACA23012, NACA0012, NACA4412 ve NACA 2412 değerlerine yönelik elde edilen veriler kıyaslanmıştır.

Tablo3. NACA Kanat Profilinin Belirlenmesi

\begin{tabular}{lccccc}
\hline $\begin{array}{l}\text { Kanat } \\
\text { Profili }\end{array}$ & $C_{L m a x}$ & $C_{D, 0}$ & $C_{\mathrm{M}, \mathbf{0}}$ & $\begin{array}{c}C_{L}{ }^{1 / 2} \\
\boldsymbol{C}_{\mathrm{D}}\end{array}$ & $\begin{array}{c}\boldsymbol{\alpha}_{C L} \\
\max \end{array}$ \\
\hline NACA & & & & & \\
23012 & 1,0843 & 0,00587 & $-0,0067$ & 177,3931 & 9 \\
NACA & & & & & \\
0012 & 0,6195 & 0,0054 & 0 & 145,7562 & 5 \\
NACA & & & & & \\
4412 & 1,2002 & 0,00678 & $-0,1032$ & 161,5835 & 7 \\
NACA & & & & & \\
2412 & 0,803 & 0,00568 & $-0,0525$ & 157,7646 & 5 \\
\hline
\end{tabular}

En iyi menzil şartlarının hesaplanması ile en uygun kanat profilinin belirlenmesi sağlanacaktır. Bu kapsamda;
$\frac{\mathrm{D}}{\mathrm{V}}=\frac{\left(\mathrm{C}_{\mathrm{D}} \frac{1}{2} \rho \mathrm{V}^{2} \mathrm{~S}\right)}{\mathrm{V}}=2 \rho S V \mathrm{C}_{\mathrm{D}}=\frac{1}{2} \rho \mathrm{S} \sqrt{\frac{\mathrm{W}}{\frac{1}{2 \rho \mathrm{S}}}} \frac{\mathrm{C}_{\mathrm{D}}}{\mathrm{C}_{\mathrm{L}_{\max }}{ }^{1 / 2}}$

Verilen bir irtifa değeri ve ağırlıkta $\frac{C_{D}}{C_{L m a x}{ }^{1 / 2}}$ minimum olduğunda menzil en uzun ve böylece $\frac{C_{L m a x}{ }^{1 / 2}}{C_{D}}$ değeri de maksimum olmaktadır. Bu kapsamda NACA 4412 kanat profilinin diğer profillere kıyasla en yüksek değeri sağladığ görülmektedir. Söz konusu verilere dayanarak tasarlanan kanat Şekil 3 'te görülmektedir.

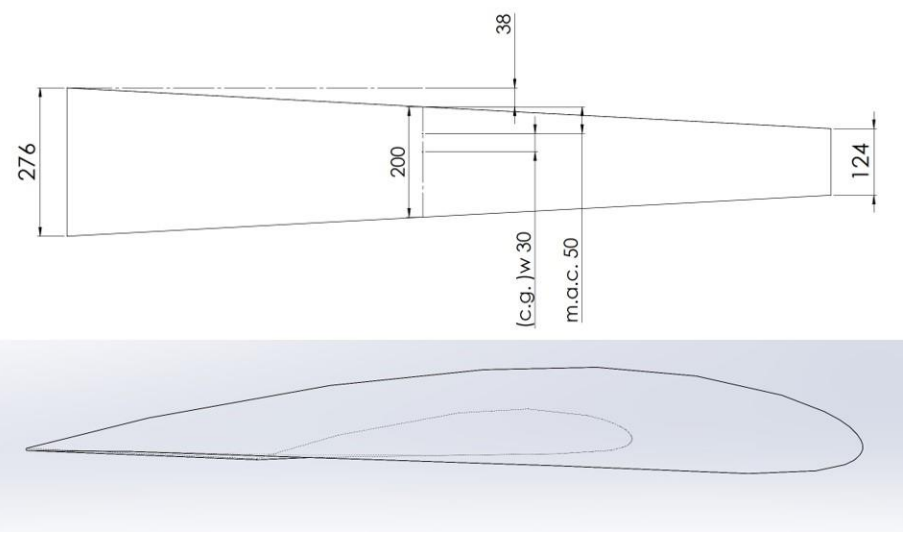

Şekil 3. NACA 4412 Kanat Profili

\subsection{Ağırlık Merkezi Hesaplaması}

Bir hava aracının ağırlık merkezi (c.g) uçuş kararlılığı açısından oldukça önemlidir. Boeing 737 Max kazalarında da olduğu üzere uçuşta kararsızlık nedeniyle birçok ciddi hava aracı kazası meydana gelmiştir (Saraçyakupoğlu, 2020). Bu çalışmada bahse konu, İHA'nın ağırlık merkezinin hesaplanması için basınçlandırılmış hava tankı da hesaba katılmaktadır. Sonuçta 23 numaralı eşitlik ortaya çıkmaktadır.

$\tilde{\mathrm{x}}=$

$\mathrm{x}_{\text {gövde }} \cdot \mathrm{W}_{\text {gövde }}+\mathrm{x}_{\text {faydalı yük }} \cdot \mathrm{W}_{\text {faydalı yük }}+\mathrm{x}_{\text {basınçlandırılmıș hava tankı }} \cdot \mathrm{W}_{\text {basınçlandırıl }}$ $\mathrm{W}_{\text {gövde }}+\mathrm{W}_{\text {faydalı yük }}+\mathrm{W}_{\text {basınçlandırılmış hava tankı }}$

Burada $\tilde{\mathrm{x}}$ kütle merkesi, $\mathrm{x}_{\text {gövde }}$ burundan olan mesafe, $\mathrm{W}_{\text {gövde }}$

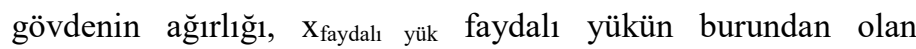
mesafesi, $\mathrm{W}_{\text {faydalı yük faydalı yükün ağırlığı, }} \mathrm{x}_{\text {basınçlandırılmıs hava tankı }}$ basınçlandırılmış hava tankının burundan olan mesafesi, and

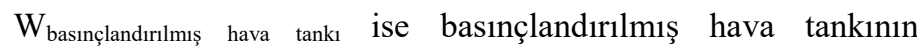
ağırlığıdır.

Sonuçta;

$\tilde{\mathrm{x}}=333 \mathrm{~mm}$

(kanat dahil edilmeden) hesaplanmaktadır.

Kanatın İHA üzerideki yerleşiminde

$\tilde{\mathrm{x}}=333=\mathrm{m} \cdot \mathrm{a} \cdot \mathrm{c}_{\cdot \mathrm{wing}}=333 \mathrm{~mm}$ 
kullanılmıştır. Burada m.a.c. ortalama aeronidamik merkez (Mean Aerodynamic Center) olarak belirlenmiştir.

\subsection{Yatay ve Dikey Kuyruk Tasarımı}

Uçağın kuyruk kısmı, yatay ve dikey kararlılığı en fazla etkileyen bölme olarak değerlendirilmektedir. Bu bölgenin tasarımı hava aracının tasarımı içinde en önemli kısımlardan birisi olarak değerlendirilmektedir. Yatay ve dikey kuyruk profillerinin belirlenmesinde kanat profilinin belirlenmesi ile aynı yöntem kullanılmıştır. NACA profil hesaplamaları yöntemi kullanılarak yapılan mukayese çalışması Tablo 4'te sunulmaktadır.

Tablo 4. NACA Profil Yöntemi İle Yatay ve Dikey Kuyruk Hesaplaması

\begin{tabular}{lcccc}
\hline & $\mathbf{C l}_{\max }$ & $\mathbf{C d}_{\boldsymbol{\alpha}}=\mathbf{0}$ & $(\mathbf{C l} / \mathbf{C d})_{\max }$ & $\boldsymbol{\alpha}_{\text {stall }}$ \\
\hline NACA0006 & 0,77 & 0,004 & 78,726 & 7 \\
NACA0009 & 1,284 & 0,005 & 99,625 & 12 \\
NACA0012 & 1,562 & 0,005 & 107,754 & 16 \\
NACA0015 & 1,653 & 0,006 & 107,769 & 18 \\
NACA0018 & 1,64 & 0,006 & 108,472 & 18 \\
NACA0021 & 1,589 & 0,007 & 103,992 & 19 \\
NACA0024 & 1,526 & 0,007 & 95,12 & 19 \\
\hline
\end{tabular}

XFLR5 kuyruk profili belirleme yazılımı ile yapılan çalışma sonrasında NACA 009 profilinin çift kuyruk profili açısından en uygun profil olduğu belirlenmiştir.

Yapılan hesaplamalar sonucunda tasarlanan kuyruk kısmı Şekil 4'te sunulmaktadır.

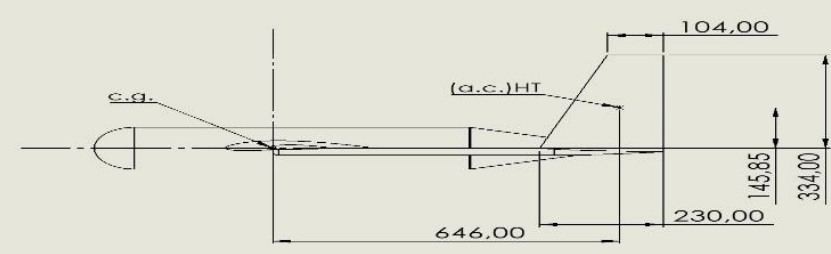

Şekil 4. IHA Gövdesi Üzerinde Kanat ve Empenaj Yerleşimi

\subsection{Gövde Tasarımı}

İHA'nın üzerindeki her bir komponent bölge olarak ele alınmış halde bilgsayar tabanlı yapılan ağırlık ve mesafe hesapları Tablo 5'te sunulmaktadır.

Tablo 5. Weight, Longitudinal and Vertical C.G. Location of Each Component

\begin{tabular}{lccc}
\hline \multicolumn{1}{c}{ IHHA Bölgesi } & $\begin{array}{c}\text { Ăğırlık } \\
\text { (gr) }\end{array}$ & $\begin{array}{c}\text { Ăğırlık Merkezi } \\
\text { Yatay Mesafesi } \\
(\mathbf{m m})\end{array}$ & $\begin{array}{c}\text { Ağırlık Merkezi } \\
\text { Dikey Mesafesi } \\
(\mathbf{m m})\end{array}$ \\
\hline Gövde & 2313 & 428,33 & 0 \\
$\begin{array}{l}\text { Kanat } \\
\text { Kuyruk Bölgesi } \\
\text { (Yatay ve Dikey }\end{array}$ & 2375 & 364,7 & 6,8 \\
$\begin{array}{l}\text { Kuyruk Yekpare } \\
\text { Hesaplanmıstır) }\end{array}$ & 1429 & 886,03 & 113,17 \\
$\begin{array}{l}\text { Basıçlandırılmış } \\
\text { Hava Tankı }\end{array}$ & 200 & 450 & \\
Faydalı Yük & 2000 & 210 & 0 \\
Ortalama & 8317 & 467,812 & 0 \\
\hline
\end{tabular}

Yapılan çalışma sonrasında Tablo 5'e uygun olarak İHA üzerindeki lokasyonlama çalışmasının sonucu Şekil 5'te sunulmaktadır.

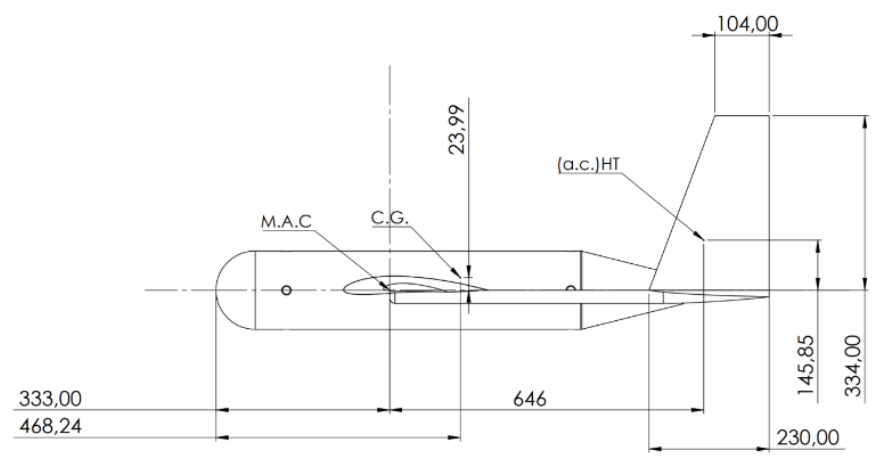

Şekil 5. IHA Üzerindeki Gövde, Kanat, Kuyruk Bölgelerinin
Yerleşimi

İHA'nın gövde tasarım kriterlerinde yunuslama, yatış ve sapma hareketlerini sağlaması için her bir kumanda sistemine yönelik lüle (nozzle) yerleştirilmesi sağlanmıştır. Söz konusu İHA'nın katı model tasarımı ise Şekil 6'da sunulmaktadır.

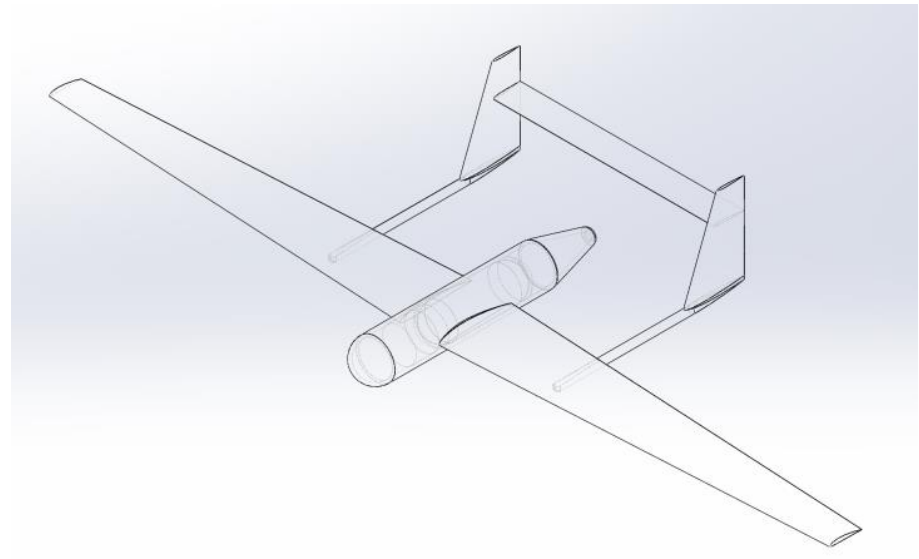

Şekil 6. IHA'nın Katı Model Tasarımı

\subsection{Lüle (Nozzle) Yerleşimi}

Lüleler yunuslama, yatış ve sapma hareketlerini en uygun şekilde verecek yerlere konuşlandırılmışlardır. Bu kapsamda İHA üzerine Şekil 7'de görüldüğü üzere bir konumlandırma gerçekleştirilmiştir. Lülelerin çalışma prensibi eşdeniklik ilkesinde ele alınmış ve bu sayede çift taraflı etki (dual-impact) sağlanmıştır.

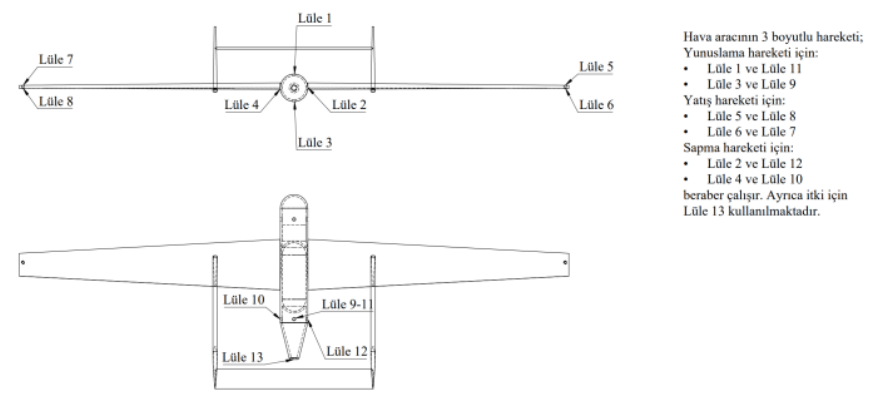

Şekil 7. Lülelerin IHA üzerinde yerleşimi 


\section{Sonuç}

Bir İHA'da itki ve manevra hareketlerinde gövde içi basınçlı hava kullanımına yönelik bilgisayar destekli yapılan çalışmaların sonucunda elde edilen veriler aşağıda sunulmaktadır.

- Optimize edilmiş verilere dayanarak bir İHA tasarımı gerçekleştirildiği ve tasarımın pratiğe aktarılmasının mevcut teknik bilgi paketi ile mümkün olduğu değerlendirilmektedir.

- Basınçlandırılmış hava ile sağlanan tahrik mekanizmalarının hem asli hem de destek üniteler olarak kullanılmasının daha az fosil yakıt kullanımı sağlamasının mümkün olduğu gözlemlenmiştir.

- Bir hipotez olarak, hava araçlarında ailerion, kuyruk dümeni, irtifa dümeni gibi kumanda yüzeylerinin yerine basınçlı hava sistemiyle çalışan lülelerin kullanılmasının kolaylık sağlayacağı ortaya konmuştur.

\section{Kaynakça}

Ateş, H., Düzgün, M. (2020). İnsansız Hava Araçları. Temel Bilgiler ve Kullanım Alanları. Ankara, Nobel Akademik Yayıncilık.

Hermanutz, A., Hornung, M. (2020). Aeroelastic Wing Planform Design Optimization of a Flutter UAV Demonstrator. Aerospace $7, \quad$ no. 4 . 45. https://doi.org/10.3390/aerospace7040045

Küçükçelebi, A, Yaldız, E . (2020). Kablolu İHA Sistemleri ve Uygulamaları. Avrupa Bilim ve Teknoloji Dergisi, Ejosat Özel Say1 2020 (ICCEES) , 154-159 . DOI: $10.31590 /$ ejosat. 802734

Yiğit, E., Yazar, I., \& Karakoç, T.H. (2018). İnsansız Hava Aracı (IHA)'nın Kapsamlı Sınıflandırılması ve Gelecek Perspektifi. Sürüdülebilir Havacılık Araştırmaları Dergisi, 3 (1): 13-19

Ulloa, C., Nunez, J.M., Lin, C, Rey, G. (2018). AHP-based design method of a lightweight, portable and flexible air-based PV$\mathrm{T}$ module for UAV shelter hangars. Renew Energy, 123:767e80.

Özbek, E., Yalin, G., Ekici, S., Karakoç, T. H., (2020). Evaluation of design methodology, limitations, and iterations of a hydrogen fuelled hybrid fuel cell mini UAV, Energy, Volume 213, 118757, https://doi.org/10.1016/j.energy.2020.118757

Wang, B., Zhao, D., Li, W., Wang, Z., Huang, Y., You, Y., \& Becker, S. (2020). Current technologies and challenges of applying fuel cell hybrid propulsion systems in unmanned aerial vehicles. Progress in Aerospace Sciences, 116, 100620. doi:10.1016/j.paerosci.2020.100620

Goh, G. D., Agarwala, S., Goh, G. L., Dikshit, V., Sing, S. L., \& Yeong, W. Y. (2017). Additive manufacturing in unmanned aerial vehicles (UAVs): Challenges and potential. Aerospace Science and Technology, 63, 140-151. doi:10.1016/j.ast.2016.12.019

Saraçyakupoğlu, T. (2020). Emniyet İrtifasından Bilgiler: Genel Havacılık, Üretim ve Bakım Süreçleri. Ankara, Nobel Akademik Yayıncilık.

Raymer, D. P., \& American Institute of Aeronautics and Astronautics. (1989). Aircraft Design: A Conceptual Approach. Washington, D.C: American Institute of Aeronautics and Astronautics.

Saraçyakupoğlu, T . (2020). Havacılıkta Organizasyonel Kazalar: B-737 Max Uçak Kazalarının Mühendislik Perspektifinden İncelenmesi . Mühendis ve Makina , 61, 701, 241-261.DOI: 10.46399/muhendismakina. 741842 